\title{
Association between Circulation Indole-3-Acetic Acid Levels and Stem Cell Factor in Maintenance Hemodialysis Patients: A Cross-Sectional Study
}

\author{
Ping-Hsun $\mathrm{Wu}^{1,2,3,4}{ }^{1}$, Yi-Ting Lin ${ }^{1,2,4,5}$, Pei-Yu Wu ${ }^{1,3,6}$, Hei-Hwa Lee ${ }^{6}$, Su-Chu Lee ${ }^{3}$, \\ Szu-Chun Hung ${ }^{7}$, Szu-Chia Chen $\left.{ }^{1,2,3,8}{ }^{(}\right)$, Mei-Chuan Kuo ${ }^{2,3,9, *}$ and Yi-Wen Chiu ${ }^{2,3,9}$ \\ 1 Graduate Institute of Clinical Medicine, College of Medicines, Kaohsiung Medical University, \\ Kaohsiung 807, Taiwan; 970392@kmuh.org.tw (P.-H.W.); yi-ting.lin@medsci.uu.se (Y.-T.L.); \\ wpuw17@gmail.com (P.-Y.W.); scarchenone@yahoo.com.tw (S.-C.C.) \\ 2 Faculty of Medicine, College of Medicine, Kaohsiung Medical University, Kaohsiung 807, Taiwan; \\ chiuyiwen@kmu.edu.tw \\ 3 Division of Nephrology, Department of Internal Medicine, Kaohsiung Medical University Hospital, \\ Kaohsiung 807, Taiwan; suchle5910@gmail.com \\ 4 Department of Medical Sciences, Uppsala University, Uppsala 75105, Sweden \\ 5 Department of Family Medicine, Kaohsiung Medical University Hospital, Kaohsiung 807, Taiwan \\ 6 Department of Laboratory Medicine, Kaohsiung Medical University Hospital, Kaohsiung 807, Taiwan; \\ 770149@kmuh.org.tw \\ 7 Division of Nephrology, Taipei Tzu Chi Hospital, Buddhist Tzu Chi Medical Foundation, \\ and School of Medicine, Tzu Chi University, Hualien 23142, Taiwan; szuchun.hung@gmail.com \\ 8 Department of Internal Medicine, Kaohsiung Municipal Siaogang Hospital, Kaohsiung Medical University, \\ Kaohsiung 81267, Taiwan \\ 9 Faculty of Renal Care, College of Medicine, Kaohsiung Medical University, Kaohsiung 807, Taiwan \\ * Correspondence: mechku@kmu.edu.tw; Tel.: +886-7-312-1101 (ext. 7351)
}

Received: 1 December 2019; Accepted: 29 December 2019; Published: 2 January 2020

\begin{abstract}
Protein-bound uremic toxin is a cardiovascular (CV) risk factor for patients with end-stage renal disease. Indole-3-acetic acid (IAA) was found to be associated with CV disease but the detailed pathophysiology remains unknown. Moreover, mitogen-activated protein kinase (MAPK) signaling cascades play an important role in the pathogenesis of $\mathrm{CV}$ disease. Thus, we explored the association between circulating IAA levels and forty MAPK cascade associated proteins in patients undergoing hemodialysis (HD). Circulating total form IAA was quantified by mass spectrometry and forty MAPK cascade associated proteins by a proximity extension assay in 331 prevalent HD patients. Accounting for multiple testing, and in multivariable-adjusted linear regression models, circulating total form IAA levels were positively associated with stem cell factor ( $\beta$ coefficient $0.13,95 \%$ confidence interval 0.04 to $0.21, p=0.004$ ). A bioinformatics approach using the search tool for interactions of chemicals (STITCH) tool provided information that IAA may be involved in the regulation of cell proliferation, hematopoietic cells, and the Janus kinase (JAK)-signal transducer and activator of transcription (STAT) signaling pathway. The knowledge gained here can be generalized, thereby impacting the non-traditional CV risk factors in patients with kidney disease. Further in vitro work is necessary to validate the translation of the mechanistic pathways.
\end{abstract}

Keywords: uremic toxins; indole-3-acetic acid; proteomics; mitogen-activated protein kinase cascade proteins; hemodialysis 


\section{Introduction}

Cardiovascular (CV) disease is the leading cause of death in patients with chronic kidney disease [1,2]. Prospective cohort studies have emphasized the importance of renal dysfunction and proteinuria on CV disease beyond the traditional risk factors (e.g., hypertension, dyslipidemia, and diabetes) [2-4]. Although several non-traditional CV risk factors have been proposed, protein-bound uremic toxins are an emerging issue in this field [5]. The accumulation of indoxyl sulfate (IS), which is the most well-investigated protein-bound uremic toxin, can cause vascular dysfunction in experimental animals and humans with CKD [6-9]. The potential pathological mechanism involves aggravating inflammation and oxidative stress, impaired endothelial function and its repair system [10]. However, there is a lack of studies investigating the $\mathrm{CV}$ impact of other protein-bound uremic toxins, such as other indole metabolites.

Indole-3-acetic acid (IAA) is an important indole metabolite metabolized from tryptophan fermentation by the gut microbiome [11,12]. It is reported to predict mortality and cardiovascular events in CKD patients [13]. Indeed, IAA increased tissue factor expression in human endothelial cells, peripheral blood mononuclear cells, vascular smooth muscle cells (VSMCs) by aryl hydrocarbon receptor (AHR) activation [14-16]. In addition, IAA mediated oxidative stress by increasing reactive oxygen species (ROS) production and increased the expression of inflammatory genes (interleukin-6 (IL-6), interleukin-8 (IL-8), intracellular adhesion molecule 1 (ICAM-1), and monocyte chemoattractant protein-1 (MCP-1)) in endothelial cells [13]. IAA is also positively correlated with C-reactive protein (CRP) [13], IL-6 [17], vascular cell adhesion molecule 1 (VCAM-1) [18], and MCP-1 level [17]. IAA activates the mitogen-activated protein kinase (MAPK) pathway in different cell types $[13,14,16,19,20]$, which are likely to play an important role in the pathogenesis of CV disease, especially in cardiac hypertrophy and cardiac remodeling after myocardial infarction [21,22]. Therefore, we hypothesized that IAA may correlate with proteins that triggered MAPK cascade and further link CV disease in CKD subjects. The proteins triggering MAPK cascade are classified according to Gene Ontology (GO) biological process and selected from the Olink cardiovascular panel. Herein, the association between circulating IAA level and MAPK cascade associated proteins was investigated in a clinical setting to explore potential new CV signaling in patients undergoing hemodialysis (HD).

\section{Experimental Section}

\subsection{Subjects}

Patients aged over 30 years of age undergoing maintenance hemodialysis (HD) for at least 90 days were recruited from two hospital-based dialysis units (Kaohsiung Medical University Hospital and Kaohsiung Municipal Hsiao-Kang Hospital) from 1 August 2016 to 31 January 2017. All participants received regular HD with high-flux dialyzers three times per week at 250 to $300 \mathrm{~mL} / \mathrm{min}$ blood flow rate, $500 \mathrm{~mL} / \mathrm{min}$ on dialysate flow, lasting $3.5-4 \mathrm{~h}$ per session and received adequate HD therapy $(\mathrm{Kt} / \mathrm{V}$ $>1.2$ ). HD participants were educated and followed the renal nutrition guideline recommendation (energy intake of $30 \mathrm{kcal} / \mathrm{kg}$ ideal body weight/day and dietary protein $1.2 \mathrm{~g} / \mathrm{kg} /$ day) [23,24]. All subjects gave written informed consent form and the protocol was approved by the Institutional Review Board of Kaohsiung Medical University (KMUHIRB-E(I)-20160095 and KMUHIRB-E(I)-20180139).

\subsection{Comorbidity and Biochemical Measurements}

An electronic healthcare record system was used to access baseline records. Individual information including age, sex, the primary cause of kidney failure (hypertension, diabetes, glomerulonephritis, and others), time on dialysis, dialysis access (fistula vs. graft), medical history, medication treatment, and biochemical data for all participants was recorded. Diabetes mellitus was defined by $\mathrm{HbA} 1 \mathrm{C}$ of $6.5 \%$ or higher or taking antidiabetic medicine. Patients with a blood pressure of $140 / 90 \mathrm{mmHg}$ or higher or taking anti-hypertensive medicine were defined as hypertensive. Before their scheduled HD 
session, blood samples were obtained from patients through the arteriovenous fistula or graft before $\mathrm{HD}$ after overnight fasting and immediately stored in $-80^{\circ} \mathrm{C}$.

\subsection{Mass Spectrometry for Indole-3-Acetic Acid Measurement}

Human serum was stored at $-20{ }^{\circ} \mathrm{C}$ until analysis. The detail high-performance liquid chromatography (HPLC) tandem mass spectrometry method was used as described previously [25]. In brief, standard solutions of IAA (Sigma-Aldrich, Catalog \# 15148, St Louis, MO, USA) were prepared in acetonitrile (Fisher Scientific, Loughborough, UK) and were diluted to $10,000 \mu \mathrm{g} / \mathrm{mL}$ as stock solutions. Calibration standards were prepared by serial dilution from 0.012 to $25 \mu \mathrm{g} / \mathrm{mL}$ IAA for each analytical batch and stored at $4{ }^{\circ} \mathrm{C}$ during the period of study. Chromatographic separation was conducted using a Phenomenex Kinetex C8 column $(250 \mathrm{~mm} \times 4.6 \mathrm{~mm} \times 5 \mu \mathrm{m})$ at room temperature with a mobile phase consisting of $5 \%$ acetonitrile with $0.1 \%$ formic acid (solvent $\mathrm{A}$ ) and $95 \%$ acetonitrile with $0.1 \%$ formic acid (solvent B). Total IAA levels were measured by an Agilent 1200 HPLC (Agilent Technologies, Palo Alto, CA) coupled with an API 4000Q triple-quadrupole mass spectrometer (API 4000QTrap, Applied Biosystems/MDS SCIEX, Concord, Canada) and an electrospray ionization (ESI) source in a positive ion mode. To $30 \mu \mathrm{L}$ of serum specimen in a $1.5 \mathrm{ml}$ Eppendorf tube, $270 \mu \mathrm{L}$ of acetonitrile was added for protein precipitation. After vortex mixing and centrifugation $(8 \mathrm{~min}$, $\left.13,400 \times g, 4^{\circ} \mathrm{C}\right)$, the supernatants were transferred to clean tubes, diluted $10 \mathrm{x}$ in solvent $\mathrm{A}$, vortex-mixed for $10 \mathrm{~s}$ and filtered through a $0.22 \mu \mathrm{m}$ polyvinylidene fluoride filter into the injection vial. Then, $20 \mu \mathrm{L}$ was injected into the LC-MS/MS system to measure IAA. All controls and fortified samples were prepared in the same manner. The multiple reaction monitoring (MRM) mode was used with the characteristic fragmentation transitions. The MRM transitions, the de-clustering potential, the collision energy, and the collision cell exit potential were measured, with data acquisition and quantitative processing accomplished using the Applied Biosystems/MDS Sciex Analyst version 1.4.2 software (Foster City, CA, USA).

\subsection{Proteomic Profiling}

Target proteins that triggered MAPK cascade were selected from the cardiovascular panel (Olink Bioscience, Uppsala, Sweden). Serum samples were analyzed with the Proseek Multiplex $96 \times 96$ proximity extension assay. The highly specific assay simultaneously measured forty MAPK cascade associated proteins (Table S1) using two specific antibodies per protein which pairwise bind to each protein, creating a polymerase chain reaction (PCR) sequence from attached oligonucleotide strands when both antibodies are bound to the target protein surface. Each sample contained two incubations, one extension, and one detection control to determine the lower detection limit and normalize the measurements. The relative concentration of the target protein was obtained [26] and $\log _{2}$-transformed for subsequent analysis. Each protein level was normalized by plate by setting the mean to zero and standard deviation to one within each plate and storage time. Mean intra-assay and inter-assay coefficients of variation were $4 \%$ and $10 \%$, respectively. Normalized protein expression (NPX) values were generated from quantitative PCR quantification cycle $(\mathrm{Cq})$ values, where higher $\mathrm{Cq}$ corresponds to lower protein abundance. Cq values (log2 scale) were corrected for technical variation by an inter-plate control.

\subsection{Statistical Analysis}

For the baseline demographic data, continuous variables were presented as mean \pm standard deviation (SD) or median with interquartile range (IQR), with ordinal and nominal variables as percentages. For the first analysis phase, the associations between the total concentration of IAA with the forty MAPK cascade associated proteins were investigated using linear regression models adjusting for age, sex and multiple testing by false discovery rate (FDR) $<5 \%$. Proteins with significant associations were investigated in the next phase. FDR was calculated according to the original version of Benjamini and Hochberg (1995) [27], which was the likelihood of incorrect rejection of a hypothesis. 
In addition, the cardiovascular proteins related to protein-bound uremic toxins were ranked by ascending $p$-value, with bootstrapped confidence intervals around the ranks. In the second phase, the independent association was investigated using multivariable-adjusted models, which included covariates age, sex, hemodialysis duration, cause of end-stage renal disease (ESRD), arteriovenous shunt type, diabetes mellitus, hypertension, dyslipidemia, antiplatelet/warfarin, anti-hypertensive drugs, diabetic treatment drugs, calcium, phosphate, high sensitivity C-reactive protein (hsCRP), and total $\mathrm{Kt} / \mathrm{V}$, all assessed at baseline. Linear associations between circulating total IAA level and selected MAPK cascade associated proteins cardiovascular proteins which were statistically significant in the first phase analysis were further investigated using linear regression splines. All the statistical methods were performed using Stata (version 15, College Station, TX, USA). Results were reported as a beta coefficient $(\beta)$ with a $95 \%$ confidence interval $(\mathrm{CI})$, and a two-tailed $p<0.05$ was considered statistically significant in the second phase analysis.

\subsection{Pathway Analysis}

To link the potential mechanism between IAA and SCF, a network was constructed by the Search Tool for Interactions of Chemicals (STITCH) 5.0 tool (available at http://stitch.embl.de/) [28] to identify the biological pathways. The STITCH tool conducts enrichment analysis on an open-source database containing 500,000 chemicals, 9.6 million proteins, and 1.6 billion interactions. The database is maintained by the European Molecular Biology Laboratory, the Swiss Institute of Bioinformatics, and the Center for Protein Research. The annotation study of the whole network provides another level of understanding of disease mechanism. To find direct interactions, the network analysis of IAA and the whole protein interaction to SCF were constructed. A "combined score" was computed from the four scores of protein-chemical interactions entitled "prediction", "experimental", "database" and "text mining" in the STITCH tool. In addition, we only considered the shortest paths (allowing no more than five interactions with the highest confidence score $>0.9$ to ensure a high level of confidence for the interaction) connecting SCF and associated protein with IAA. For this purpose, the enrichment analysis of networks related to biological processes, molecular function, and the Kyoto Encyclopedia of Genes and Genomes (KEGG) pathway was also studied using the STITCH 5.0 Resource. The statistical significance was determined by the Bonferroni corrected $p$-value $<0.05$.

\section{Results}

In total, 341 HD patients were enrolled and MAPK cascade associated proteins were measured by proximity extension assays. Subjects with low-quality proteomics data $(n=10)$ were excluded. Finally, the association between total IAA level and forty MAPK cascade associated proteins was analyzed in 331 HD patients (Figure 1).

\subsection{Demographic and Clinical Characteristics}

The characteristics of the included patients are listed in Table 1. The mean age of the HD patients was $59.3 \pm 11.6,53.5 \%$ were male, $77.3 \%$ had hypertension, and $43.5 \%$ had diabetes. The major cause of ESRD was diabetes (35.3\%) and glomerulonephritis (35.3\%). The median (IQR) years of dialysis vintage were $5(10)$ and most of the vascular access in these patients was arteriovenous fistula $(87.6 \%)$. The median (IQR) serum level of ionized calcium was $4.6(0.64) \mathrm{mg} / \mathrm{dl}$, phosphate was $4.6(1.4) \mathrm{mg} / \mathrm{dl}$, hsCRP was 0.83 (2.68) $\mathrm{mg} / \mathrm{l}$ and total IAA level was $0.92(1) \mu \mathrm{g} / \mathrm{mL}$ (Table 1). The mean NPX value of MAPK cascade associated proteins is shown in Table S1. 
Prevalent hemodialysis patients recruited for indole-3-acetic acid and mitogen-activated protein kinase cascade associated proteins measurement $(N=341)$

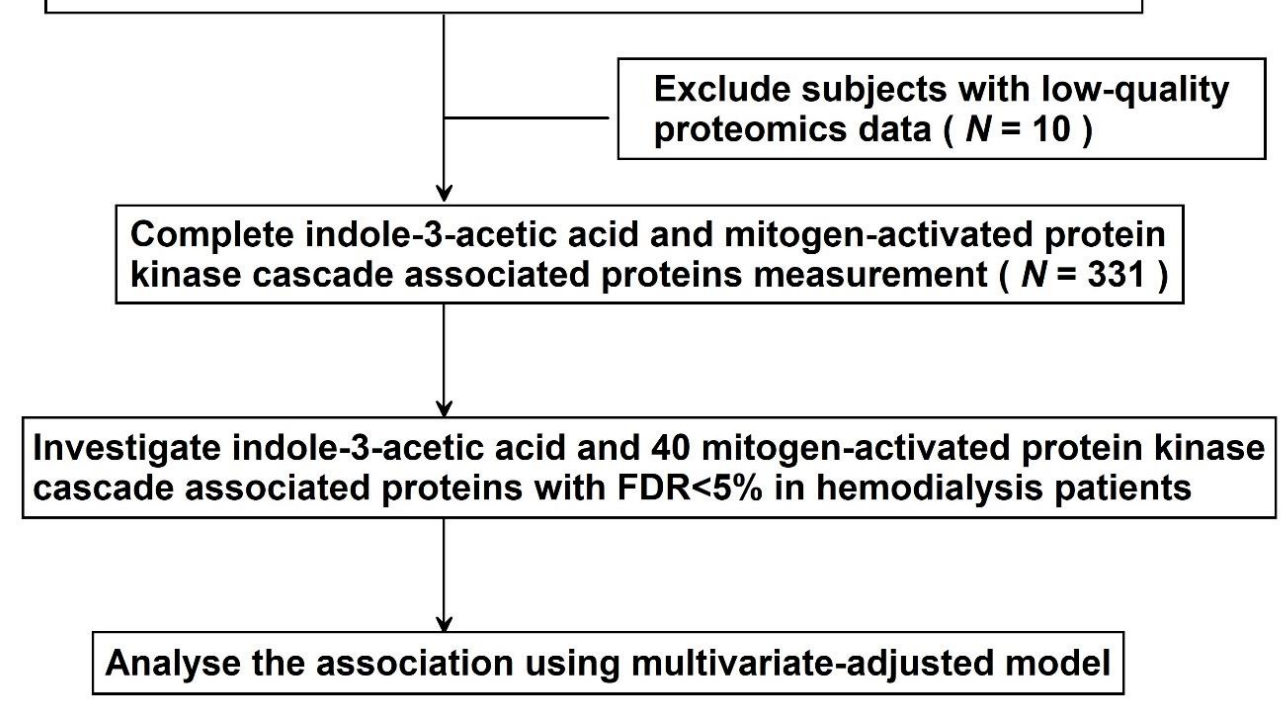

Figure 1. Study design.

Table 1. Baseline characteristics of 331 hemodialysis participants.

\begin{tabular}{|c|c|}
\hline & $N=331$ \\
\hline Age (years) & $59.3 \pm 11.6$ \\
\hline Male & $177(53.5 \%)$ \\
\hline Smoking & $36(10.9 \%)$ \\
\hline Hemodialysis duration, years & $5(10)$ \\
\hline Body mass index, $\mathrm{kg} / \mathrm{m}^{2}$ & $23.6(4.8)$ \\
\hline \multicolumn{2}{|l|}{ Cause of ESRD } \\
\hline Hypertension & $36(10.9 \%)$ \\
\hline Diabetes Mellitus & $117(35.3 \%)$ \\
\hline Glomerulonephritis & $117(35.3 \%)$ \\
\hline Others * & $61(18.4 \%)$ \\
\hline \multicolumn{2}{|l|}{ Arteriovenous shunt } \\
\hline Arteriovenous fistula & $290(87.6 \%)$ \\
\hline Arteriovenous graft & $41(12.4 \%)$ \\
\hline \multicolumn{2}{|l|}{ Comorbidities } \\
\hline Diabetes mellitus & $144(43.5 \%)$ \\
\hline Hypertension & $256(77.3 \%)$ \\
\hline Dyslipidemia & $126(38.1 \%)$ \\
\hline \multicolumn{2}{|l|}{ Medications } \\
\hline Antiplatelets/Warfarin & $95(28.7 \%)$ \\
\hline Anti-hypertensive drugs & $156(47.1 \%)$ \\
\hline Diabetic treatment drugs & $111(33.5 \%)$ \\
\hline \multicolumn{2}{|l|}{ Laboratory data } \\
\hline Albumin, g/dL & $3.87 \pm 0.29$ \\
\hline Ionized Calcium, mg/dL & $4.6(0.64)$ \\
\hline Phosphate, $\mathrm{mg} / \mathrm{dL}$ & $4.6(1.4)$ \\
\hline High sensitivity C-reactive protein, $\mathrm{mg} / \mathrm{L}$ & $0.83(2.68)$ \\
\hline Total Kt/V & $1.56(0.32)$ \\
\hline Uremic toxin (total form) & \\
\hline Indole-3-acetic acid, $\mu \mathrm{g} / \mathrm{mL}$ & $0.92(1)$ \\
\hline
\end{tabular}

Continuous data are expressed as mean \pm standard deviation or median (interquartile range) and categorical data were expressed as percentages. ${ }^{*}$ Other causes of end-stage renal disease include polycystic kidney disease, tumor, systemic lupus erythematosus, gout, interstitial nephritis. 


\subsection{Discovery Phase}

Regarding the association of total IAA concentration with the forty MAPK cascade associated proteins in each HD patient after adjusting for age and sex, the circulating IAA level was positively associated with stem cell factor (SCF) and growth differentiation factor 2 (Figure 2). Considering multiple testing with an FDR of $5 \%$ (corresponding to $P=0.00125$ ), IAA was significantly associated with SCF (Figure 3). The ranking of the associations (with 95\% bootstrap-obtained CIs) of total IAA concentration with all MAPK cascade associated proteins is graphically presented, with SCF being the top hit related to IAA, with wide confidence intervals of the ranking as expected (Figure S1).

Study

ID

Coefficient $(95 \% \mathrm{Cl})$

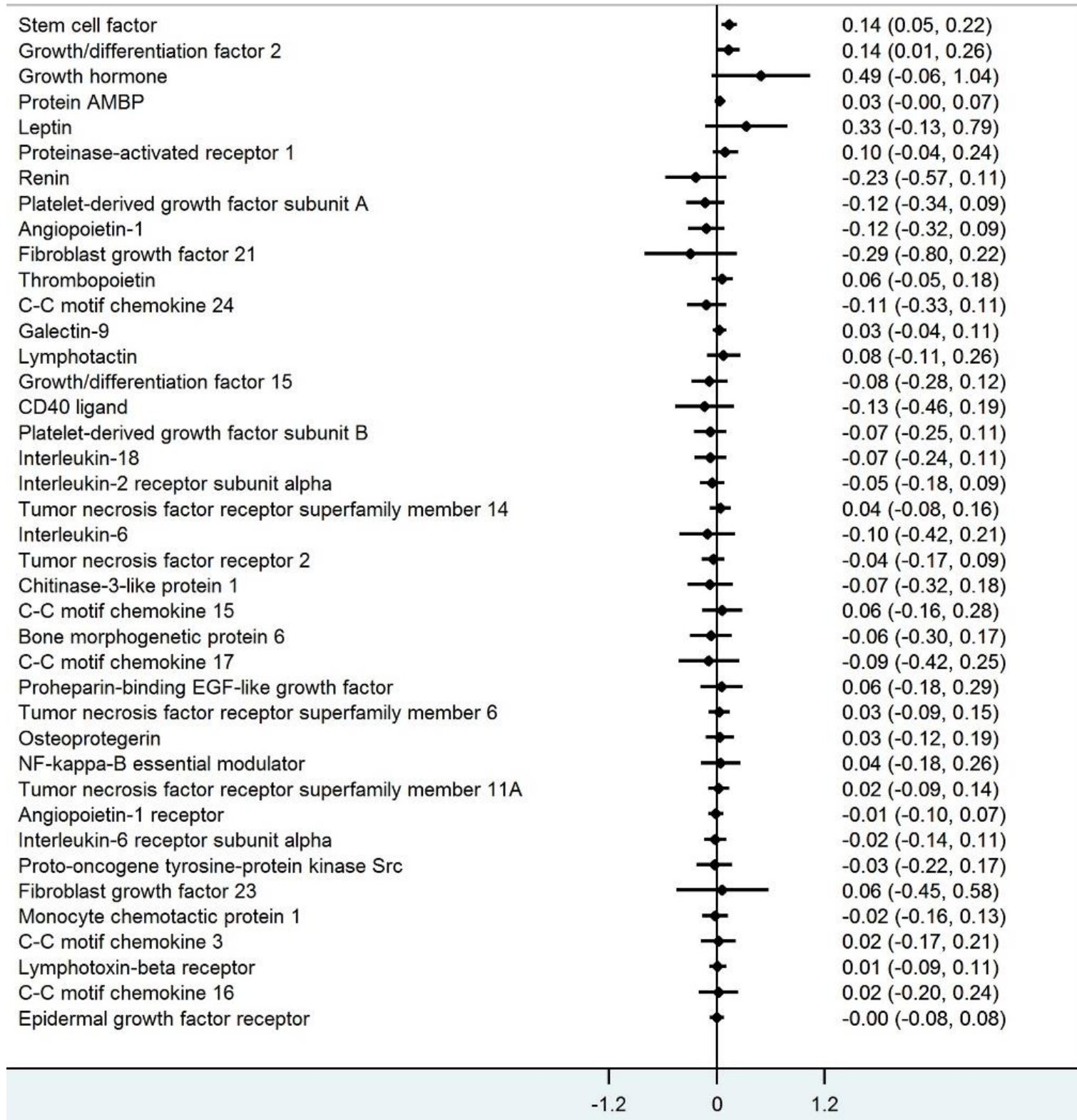

Figure 2. The association between Indole-3-acetic acid and 40 mitogen-activated protein kinase cascade associated proteins in linear regression models with age and sex adjustment. 


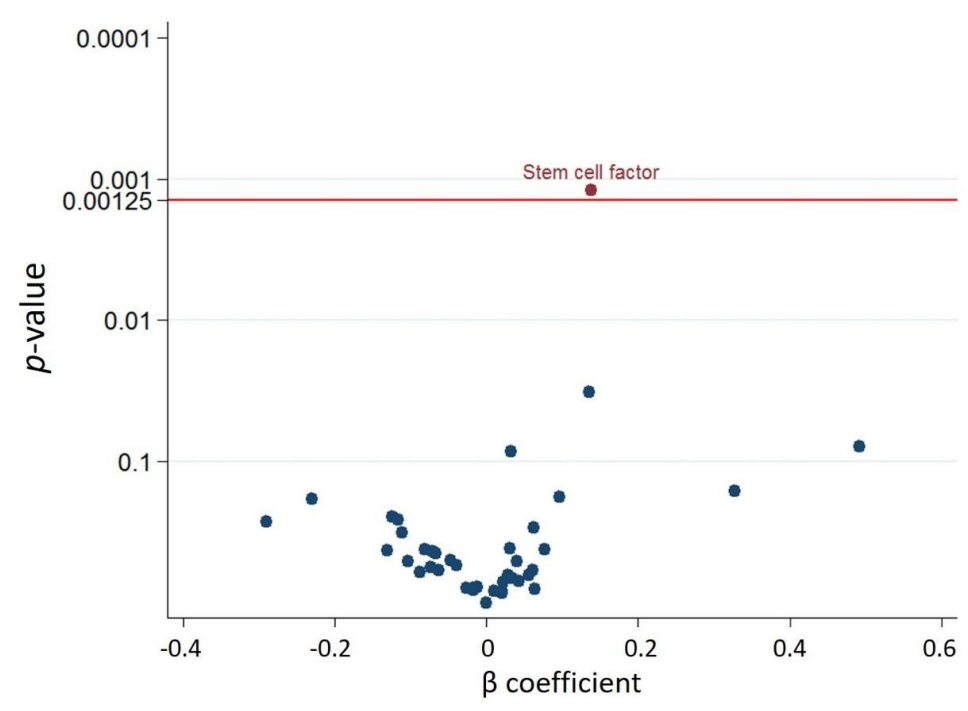

Figure 3. Volcano plot of the $p$-value and $\beta$ coefficient for Indole-3-acetic acid and 40 MAPK cascade associated proteins association with false discovery rate $<5 \%$ multiple testing control.

\subsection{Best Estimates Phase}

Regarding associations between IAA and SCF in a multivariable-adjusted linear regression model, the positive association ( $\beta$ coefficient $0.13,95 \%$ CI 0.04 to $0.21, p=0.004$ ) persisted after adjusting for baseline age, sex, smoking status, hemodialysis vintage, body mass index, cause of end-stage renal disease, arteriovenous shunt type, comorbidities (diabetes mellitus, hypertension, and dyslipidemia), medications (antiplatelet/warfarin drugs, anti-hypertensive drugs, and diabetic treatment drugs), and clinical laboratory data (serum albumin level, ionized calcium level, phosphate level, hsCRP level, and $\mathrm{Kt} / \mathrm{V}$ ) (Table 2). Linear regression spline analysis demonstrated a chiefly linear association of IAA and SCF (Figure S2).

Table 2. Associations of circulating Indole-3-acetic acid level and other clinical parameters with stem cell factor in the multivariate linear regression model.

\begin{tabular}{|c|c|c|}
\hline & $\beta$ Coefficient $(95 \% \mathrm{CI})$ & $P$-Value \\
\hline Indole-3-acetic acid $(\mu \mathrm{g} / \mathrm{mL})$ & $0.13(0.04-0.21)$ & 0.004 \\
\hline Age & $-0.0006(-0.0003-0.002)$ & 0.66 \\
\hline Sex & $-0.06(-0.12-0.003)$ & 0.063 \\
\hline Smoking & $0.01(-0.08-0.10)$ & 0.80 \\
\hline Hemodialysis duration (years) & $-0.002(-0.008-0.003)$ & 0.51 \\
\hline Body mass index $\left(\mathrm{kg} / \mathrm{m}^{2}\right)$ & $-0.001(-0.005-0.002)$ & 0.50 \\
\hline Cause of ESRD: Hypertension & $-0.02(-0.13-0.09)$ & 0.76 \\
\hline Cause of ESRD: Diabetes Mellitus & $0.12(-0.008-0.25)$ & 0.07 \\
\hline Cause of ESRD: Glomerulonephritis & $0.007(-0.08-0.09)$ & 0.86 \\
\hline Diabetes Mellitus comorbidity & $-0.15(-0.26-0.03)$ & 0.01 \\
\hline Hypertension comorbidity & $-0.03(-0.11-0.05)$ & 0.48 \\
\hline Hyperlipidemia comorbidity & $0.03(-0.04-0.09)$ & 0.42 \\
\hline Antiplatelet/warfarin & $-0.02(-0.08-0.05)$ & 0.60 \\
\hline Anti-hypertensive drugs & $-0.05(-0.11-0.02)$ & 0.18 \\
\hline Diabetic treatment drugs & $-0.02(-0.12-0.09)$ & 0.74 \\
\hline Albumin $(\mathrm{g} / \mathrm{dL})$ & $0.16(0.06-0.26)$ & 0.002 \\
\hline Ionized Calcium (mg/dL) & $-0.04(-0.1-0.03)$ & 0.24 \\
\hline Phosphate $(\mathrm{mg} / \mathrm{dL})$ & $-0.01(-0.04-0.02)$ & 0.44 \\
\hline High sensitivity C-reactive protein (mg/L) & $0.00009(-0.007-0.008)$ & 0.82 \\
\hline Total Kt/V & $0.02(-0.11-0.15)$ & 0.74 \\
\hline
\end{tabular}




\subsection{A Bioinformatics Approach to Link IAA with SCF}

In the literature, no study has investigated the direct effect of IAA on SCF. Therefore, a bioinformatics approach was used to explore potentially related pathways, integrating IAA with SCF in a metabolite-protein interaction network. According to the STITCH interaction network, IAA was linked to SCF (Kit ligand) through two interacting key proteins (S-phase kinase-associated protein 1 (SKP1) and Janus kinase 2 (JAK2)) (Figure 4). The functional enrichment analysis demonstrated that the link between IAA and SCF involved top biological processes (GO), including regulation of protein modification, tyrosine phosphorylation of signal transducer and activator of transcription 5 (Stat5) protein, as well as regulation of cell proliferation (Table 3). The top regulatory KEGG pathways involved included phosphoinositide-3-kinase (PI3K)/Akt signaling pathway, hematopoietic cell lineage, JAK/signal transducers and activators of transcription (JAK/STAT) signaling pathway, and cytokine-cytokine receptor interaction (Table 3). Therefore, the effect of IAA on SCF may involve PI3K/Akt and JAK/STATA pathway via two regulatory proteins (SKP1 and JAK2). These findings provide the possible mechanism to link between IAA and SCF.

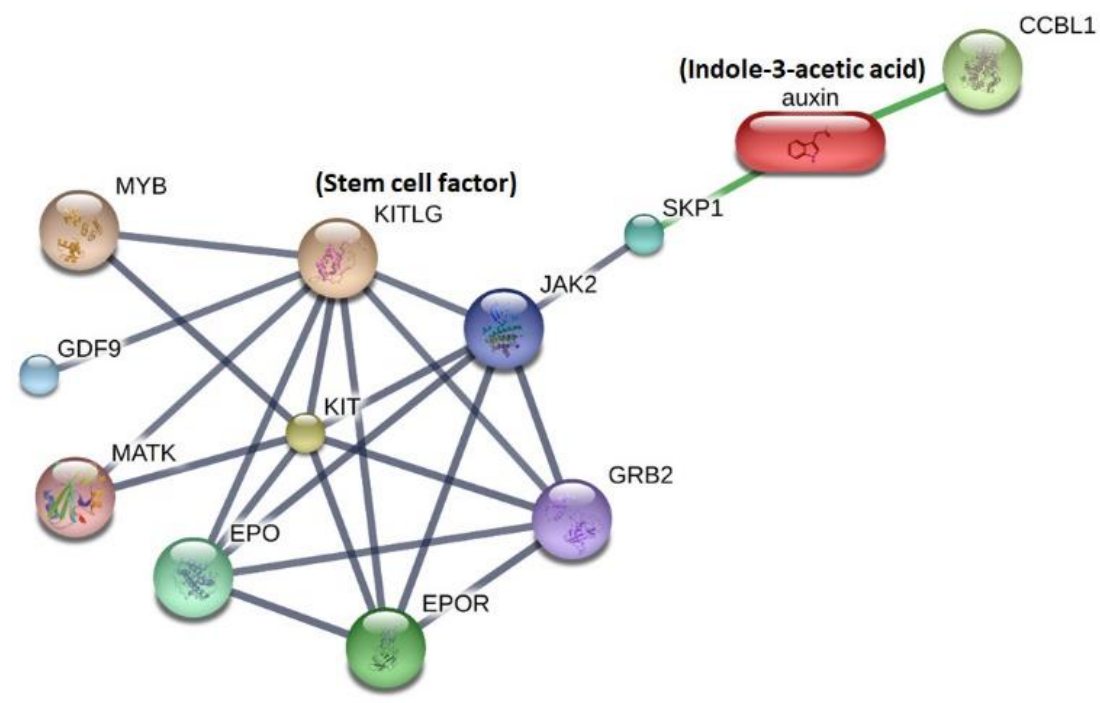

Figure 4. Network analysis results using the Search Tool for Interactions of Chemicals (STITCH) tool to explore the link between indole-3-acetic acid and stem cell factor.

Table 3. The functional enrichment analysis for investigating the link between indole-3-acetic acid and stem cell factor.

\begin{tabular}{cccc}
\hline & Functional Enrichments in Your Network & \\
\hline Pathway ID & Pathway Description & $\begin{array}{c}\text { Count in the } \\
\text { Gene Set }\end{array}$ & $\begin{array}{c}\text { Bonferroni } \\
\text { Corrected } p \text {-Value }\end{array}$ \\
\hline & Biological Process (GO) & 8 & 0.000877 \\
GO:0031399 & Regulation of protein modification process & 0.000877 \\
GO:0031401 & Positive regulation of protein modification process & 2 & 0.000877 \\
GO:0038162 & Erythropoietin-mediated signaling pathway & 0.000877 \\
GO:0042523 & Positive regulation of tyrosine phosphorylation of Stat5 protein & 3 & 0.00237 \\
GO:0008284 & Positive regulation of cell proliferation & 6 & 0.00237 \\
GO:0036018 & Cellular response to erythropoietin & 2 & 0.00237 \\
GO:0050731 & Positive regulation of peptidyl-tyrosine phosphorylation & 4 & 0.00237 \\
GO:0050776 & Regulation of immune response & 4 & 0.00276 \\
GO:0048872 & Homeostasis of number of cells & 6 & 0.00355 \\
GO:0045087 & Innate immune response & 3 & 0.00497 \\
GO:0030218 & Erythrocyte differentiation & 2 & 0.00553 \\
GO:0035234 & Ectopic germ cell programmed cell death & 3 & 0.00608 \\
GO:0034101 & Erythrocyte homeostasis & & \\
\hline
\end{tabular}


Table 3. Cont.

\begin{tabular}{|c|c|c|c|}
\hline \multicolumn{4}{|c|}{ Functional Enrichments in Your Network } \\
\hline GO:0001932 & Regulation of protein phosphorylation & 6 & 0.0084 \\
\hline GO:0031325 & Positive regulation of cellular metabolic process & 8 & 0.00915 \\
\hline GO:0002376 & Immune system process & 7 & 0.0104 \\
\hline GO:0002768 & Immune response-regulating cell Surface receptor signaling pathway & 4 & 0.0151 \\
\hline GO:0043067 & Regulation of programmed cell death & 6 & 0.0151 \\
\hline GO:0045597 & Positive regulation of cell differentiation & 5 & 0.0151 \\
\hline GO:0048070 & Regulation of developmental pigmentation & 2 & 0.0151 \\
\hline GO:1902531 & Regulation of intracellular signal transduction & 6 & 0.0151 \\
\hline GO:0043069 & Negative regulation of programmed cell death & 5 & 0.0173 \\
\hline GO:0035162 & Embryonic hemopoiesis & 2 & 0.025 \\
\hline GO:0038095 & Fc-epsilon receptor signaling pathway & 3 & 0.0261 \\
\hline GO:0030097 & hemopoiesis & 4 & 0.0305 \\
\hline GO:0042517 & Positive regulation of tyrosine phosphorylation of Stat3 protein & 2 & 0.0323 \\
\hline GO:0044344 & Cellular response to fibroblast growth factor stimulus & 3 & 0.0323 \\
\hline GO:0046777 & Protein autophosphorylation & 3 & 0.033 \\
\hline GO:0046579 & Positive regulation of Ras protein signal transduction & 2 & 0.0346 \\
\hline GO:0007173 & Epidermal growth factor receptor signaling pathway & 3 & 0.0374 \\
\hline GO:0051347 & Positive regulation of transferase activity & 4 & 0.0374 \\
\hline GO:0002520 & Immune system development & 4 & 0.0403 \\
\hline GO:0048584 & Positive regulation of response to stimulus & 6 & 0.0403 \\
\hline GO:0038083 & Peptidyl-tyrosine autophosphorylation & 2 & 0.0419 \\
\hline \multicolumn{4}{|c|}{ Kyoto Encyclopedia of Genes and Genomes (KEGG) Pathways } \\
\hline 4151 & PI3K-Akt signaling pathway & 7 & $6.42 \times 10^{-8}$ \\
\hline 4640 & Hematopoietic cell lineage & 4 & $1.92 \times 10^{-5}$ \\
\hline 4630 & Jak-STAT signaling pathway & 4 & 0.00014 \\
\hline 4060 & Cytokine-cytokine receptor interaction & 4 & 0.000836 \\
\hline 4014 & Ras signaling pathway & 3 & 0.0142 \\
\hline 5221 & Acute myeloid leukemia & 2 & 0.022 \\
\hline 4917 & Prolactin signaling pathway & 2 & 0.027 \\
\hline 5200 & Pathways in cancer & 3 & 0.027 \\
\hline 4916 & Melanogenesis & 2 & 0.0445 \\
\hline
\end{tabular}

\section{Discussion}

\subsection{Principal Observations}

This study investigated associations of total IAA concentration with forty circulating MAPK cascade proteins in an HD cohort. Accounting for multiple testing, and in multivariable-adjusted linear regression models, circulating total IAA levels were positively associated with SCF. A bioinformatics approach using the STITCH tool provided information that IAA may be involved in the regulation of cell proliferation, hematopoietic cells, and the JAK/STAT signaling pathway. We believe that the knowledge gained here can be generalized, thereby impacting the non-traditional CV risk factors in patients with kidney disease.

\subsection{The Cardiovascular Damage of IAA}

IAA derived from tryptophan by the gut microbiome [29] is a ligand of the AHR involved in atherogenesis, vascular inflammation, oxidative stress, and thrombogenicity $[15,30]$. IAA, similar to 
indoxyl sulfate, shares the same indole ring; however, the structure difference between IAA (a carboxyl group attached to the indole ring) and IS (a sulfate group attached to the indole ring) may lead to their specificity in the pattern of gene expression other than the classic pattern of AHR activation. In addition, levels of IS and IAA have usually been measured at the same time in clinical studies [14,31], but specific associations were demonstrated between two uremic toxins and clinical parameters, disputing a similar function in all indolic solutes [32-34].

IAA induces endothelial inflammation and oxidative stress in vitro, and is a significant predictor of mortality and cardiovascular events in a clinical study [13]. The toxic mechanism of IAA includes the production of tissue factor [14], activation of pro-inflammatory enzyme cyclooxygenase-2 [13], stimulation of inflammatory gene expression [13], inhibition of UDP-glucuronosyltransferase activity and mitochondrial activity [35], induction of endothelial progenitors cell apoptosis [32], promotion of platelet aggregation [13], and exacerbation of red blood cell procoagulant activity [36]. Interestingly, besides the potential role of AHR in atherogenesis [37], this receptor could also be involved in the imbalance between vascular damage/regeneration in CKD [38].

\subsection{The Potential Mechanism to Link IAA and SCF}

The IAA-activated nongenomic AHR/MAPK pathway $[13,14,16]$ triggers CV disease in CKD patients. SCF, one of the important MAPK cascade proteins, known as a ligand for the receptor-type protein-tyrosine kinase KIT, plays an essential role in cell proliferation, apoptosis, differentiation and migration in several tissues. The activity of the SCF/c-KIT system is linked with the PI3K/Akt pathway, the JAK/STAT pathway, and the MAPK pathway [39]. The average serum concentration of SCF is $3.3 \mathrm{ng} / \mathrm{mL}$ in a normal human, 5-6 fold higher in CKD and HD patients [40]. SCF contributes to vasculogenesis and tissue repair by stimulating recruitment and activation of bone marrow (BM) derived, as well as tissue-resident progenitor and stem cells [41-43]. Interestingly, high serum indole-3-acetic acid levels were associated with low $\mathrm{CD}^{+} 4^{+}$and $\mathrm{CD} 133^{+}$endothelial progenitor cells involved in vessel repair and neovascularization [32]. In addition, AHR inhibition promotes the expansion of CD34 hematopoietic stem cells ex vivo [38]. One could hypothesize that indolic uremic solutes, by activating AHR, promote a diminution of endothelial progenitor cells, leading to a deleterious effect on the endothelial repair. SCF, which is involved in vascular repair [44,45], stimulates c-Kit to promote survival, migration, as well as capillary tube formation in endothelial cells [46] and attenuates vascular smooth muscle cell apoptosis [47]. Taken together, IAA may trigger CV risk in patients with CKD. SCF may play concurrent cytoprotective factors [48] on the CV system. In our pathway analysis, we also found a link between IAA and SCF via interacting proteins SKP1 and JAK2, but this requires further investigation to validate the translation of the mechanistic pathways suggested in vitro. Further clinical and basic research is needed to establish the interaction effect between IAA and SCF in the dialysis populations. The IAA and CV outcomes association stratified by circulating SCF levels could be a clinically relevant approach. In addition, the burden of IAA could be lower through dialytic and non-dialytic strategies, such as enhancement of solute removal, devices for extracorporeal absorption, reduction of gastrointestinal absorption, and maintenance of residual renal function [14]. Since IAA is derived from the breakdown of dietary tryptophan by gut microbiota, the production can be suppressed by restricting specific dietary protein intake, manipulating the colon microbial metabolism, or reducing intestinal absorption, in order to decrease the circulating IAA level. For example, AST-120 treatment attenuated protein-bound uremic toxin accumulation in multiple organs [49], so there is a potential treatment effect for modifying IAA associated CV toxicity.

\subsection{Strengths and Limitations}

The present study used a proximity extension assay proteomics chip to detect selected proteins in the hemodialysis population, which allowed a rapid high-throughput analysis of high sensitivity and specificity. Nonetheless, this study had several limitations. First, the cross-sectional study design could not generate causal inference. Furthermore, the weak association between IAA and SCF should 
be interpreted cautiously. Second, we did not measure the free concentration of IAA. Although many studies demonstrated the free concentration of protein-bound uremic toxins (indoxyl sulfate and p-cresyl sulfate) correlated with outcomes; however, the effect of indoxyl sulfate in vitro is not influenced by albumin concentration in the media [14]. Furthermore, the experiment of mimicking in vivo conditions of indoxyl sulfate and protein binding found that the presence of human albumin did not alter the effects of IS, suggesting that cellular uptake is not hampered by protein binding [50]. Furthermore, the observed concentrations of total and free indoxyl sulfate or p-cresyl sulfate are well correlated in clinical studies [51]. Additionally, most studies investigate the total concentration of IAA and evaluate the outcome association [16-18,52-54]. Third, the protein was correlated with a single serum IAA measurement at the inclusion, without information about IAA intra-individual variability, so limitations of the results can be impacted by many factors including participants' vascular access function, diet condition, pre-analytical sampling conditions, and variation of metabolites in human. No intra-individual variability of IAA was accessed in this study. Thus, the sequential measurement of IAA might improve data quality. Fourth, the intake of tryptophan, tyrosine, and fibers from food intake was not assessed. IAA is derived from dietary protein, so circulating IAA concentrations may be influenced by dietary protein intake. Third, current research remains exploratory because there may be an alternative pathway in IAA associated with toxicity. Thus, the proposed mechanisms through which the biomarkers may be pathophysiologically related to IAA are hypothesis-generating. Finally, the circulating IAA level was not evaluated at post HD status in this study. However, studies suggest IAA is bound to albumin with a high affinity [55], estimated as an $80 \%$ protein binding ability [56]. Protein-bound solutes were difficult to remove by HD due to a combination effect that only the free fraction can be removed, such that the overall dialyzer clearance depends on the free toxin concentration and on the speed of equilibration between bound and free fractions [57]. Although IAA could be party removed during HD sessions [56], predialysis concentrations of IAA seem to depend on residual renal function rather than on dialysis adequacy, assessed by $\mathrm{Kt} / \mathrm{V}$ urea [58]. In our HD cohort, all enrolled patients were presented as anuria and limited residual renal function.

\section{Conclusions}

Circulating IAA was positively associated with circulating SCF, which contributes to cell migration/proliferation and is involved in cardiac repair. This finding may provide insights into the mechanisms that lead to higher $\mathrm{CV}$ risk in HD patients

Supplementary Materials: The following are available online at http://www.mdpi.com/2077-0383/9/1/124/s1, Figure S1. Ranking proteins by $p$-value with bootstrapped confidence intervals around the ranks related to indole-3-acetic acid, Figure S2. The regression line between the log-transformed indole-3-acetic acid level and stem cell factor NPX units; Table S1. List of 40 mitogen-activated protein kinase cascade associated proteins measured by proximity extension assay. The mean NPX value and the standard deviation was presented in 331 hemodialysis patients.

Author Contributions: Conceptualization, P.-H.W., Y.-T.L., M.-C.K., and Y.-W.C.; Data curation, P.-H.W., Y.-T.L., P.-Y.W., H.-H.L., S.-C.L., S.-C.C., M.-C.K., and Y.-W.C.; Formal analysis, P.-H.W., Y.-T.L., and H.-H.L.; Funding acquisition, P.-H.W. and M.-C.K.; Investigation, P.-H.W., Y.-T.L., P.-Y.W., H.-H.L., S.-C.L., S.-C.C., M.-C.K., and Y.-W.C.; Methodology, P.-H.W., Y.-T.L., P.-Y.W., H.-H.L., S.-C.H. and M.-C.K.; Resources, P.-H.W.; Software, Y.-T.L.; Visualization, P.-H.W.; Writing—original draft, P.-H.W.; Writing—review \& editing, S.-C.H., M.-C.K., and Y.-W.C. All authors have read and agreed to the published version of the manuscript.

Funding: The funding sources did not play any role in the design and conduct of the study, collection, management, analysis, and interpretation of the data or the formation of this manuscript. The study was funded by grants from the Ministry of Science and Technology, Taiwan (MOST 105-2628-B-037-005-MY2, MOST 106-2314-B-037-054, MOST 107-2314-B-037-104, and MOST 107-2314-B-037-021-MY2), Kaohsiung Medical University Hospital, Taiwan (KMUH103-3M08, KMUH105-5R15, KMUH106-6R17, and KMUH107-7R16), and Kaohsiung Medical University, Taiwan (KMUH106-6T03 and KMU-Q108024).

Acknowledgments: We are grateful to the staff and participants of the prospective hemodialysis cohort.

Conflicts of Interest: The authors declare no conflict of interest. 


\section{References}

1. Gansevoort, R.T.; Correa-Rotter, R.; Hemmelgarn, B.R.; Jafar, T.H.; Heerspink, H.J.; Mann, J.F.; Matsushita, K.; Wen, C.P. Chronic kidney disease and cardiovascular risk: Epidemiology, mechanisms, and prevention. Lancet 2013, 382, 339-352. [CrossRef]

2. Go, A.S.; Chertow, G.M.; Fan, D.; McCulloch, C.E.; Hsu, C.Y. Chronic kidney disease and the risks of death, cardiovascular events, and hospitalization. N. Engl. J. Med. 2004, 351, 1296-1305. [CrossRef] [PubMed]

3. Chronic Kidney Disease Prognosis, C.; Matsushita, K.; van der Velde, M.; Astor, B.C.; Woodward, M.; Levey, A.S.; de Jong, P.E.; Coresh, J.; Gansevoort, R.T. Association of estimated glomerular filtration rate and albuminuria with all-cause and cardiovascular mortality in general population cohorts: A collaborative meta-analysis. Lancet 2010, 375, 2073-2081.

4. Hemmelgarn, B.R.; Manns, B.J.; Lloyd, A.; James, M.T.; Klarenbach, S.; Quinn, R.R.; Wiebe, N.; Tonelli, M.; Alberta Kidney Disease, N. Relation between kidney function, proteinuria, and adverse outcomes. JAMA 2010, 303, 423-429. [CrossRef]

5. Cozzolino, M.; Mangano, M.; Stucchi, A.; Ciceri, P.; Conte, F.; Galassi, A. Cardiovascular disease in dialysis patients. Nephrol. Dial. Transplant. 2018, 33 (Suppl. S3), iii28-iii34. [CrossRef]

6. Meijers, B.K.; Van Kerckhoven, S.; Verbeke, K.; Dehaen, W.; Vanrenterghem, Y.; Hoylaerts, M.F.; Evenepoel, P. The uremic retention solute p-cresyl sulfate and markers of endothelial damage. Am. J. Kidney Dis. 2009, 54, 891-901. [CrossRef]

7. $\quad$ Meijers, B.K.; Claes, K.; Bammens, B.; de Loor, H.; Viaene, L.; Verbeke, K.; Kuypers, D.; Vanrenterghem, Y.; Evenepoel, P. P-cresol and cardiovascular risk in mild-to-moderate kidney disease. Clin. J. Am. Soc. Nephrol. 2010, 5, 1182-1189. [CrossRef]

8. Yamamoto, H.; Tsuruoka, S.; Ioka, T.; Ando, H.; Ito, C.; Akimoto, T.; Fujimura, A.; Asano, Y.; Kusano, E. Indoxyl sulfate stimulates proliferation of rat vascular smooth muscle cells. Kidney Int. 2006, 69, 1780-1785. [CrossRef]

9. Dou, L.; Jourde-Chiche, N.; Faure, V.; Cerini, C.; Berland, Y.; Dignat-George, F.; Brunet, P. The uremic solute indoxyl sulfate induces oxidative stress in endothelial cells. J. Thromb. Haemost. 2007, 5, 1302-1308. [CrossRef]

10. Yu, M.; Kim, Y.J.; Kang, D.H. Indoxyl sulfate-induced endothelial dysfunction in patients with chronic kidney disease via an induction of oxidative stress. Clin. J. Am. Soc. Nephrol. 2011, 6, 30-39. [CrossRef]

11. Jourde-Chiche, N.; Dou, L.; Cerini, C.; Dignat-George, F.; Vanholder, R.; Brunet, P. Protein-bound toxins-update 2009. Semin. Dial. 2009, 22, 334-339. [CrossRef] [PubMed]

12. Fernandez-Prado, R.; Esteras, R.; Perez-Gomez, M.V.; Gracia-Iguacel, C.; Gonzalez-Parra, E.; Sanz, A.B.; Ortiz, A.; Sanchez-Nino, M.D. Nutrients turned into toxins: Microbiota modulation of nutrient properties in chronic kidney disease. Nutrients 2017, 9, 489. [CrossRef] [PubMed]

13. Dou, L.; Sallee, M.; Cerini, C.; Poitevin, S.; Gondouin, B.; Jourde-Chiche, N.; Fallague, K.; Brunet, P.; Calaf, R.; Dussol, B.; et al. The cardiovascular effect of the uremic solute indole-3 acetic acid. J. Am. Soc. Nephrol. 2015, 26, 876-887. [CrossRef] [PubMed]

14. Gondouin, B.; Cerini, C.; Dou, L.; Sallee, M.; Duval-Sabatier, A.; Pletinck, A.; Calaf, R.; Lacroix, R.; Jourde-Chiche, N.; Poitevin, S.; et al. Indolic uremic solutes increase tissue factor production in endothelial cells by the aryl hydrocarbon receptor pathway. Kidney Int. 2013, 84, 733-744. [CrossRef]

15. Chitalia, V.C.; Shivanna, S.; Martorell, J.; Balcells, M.; Bosch, I.; Kolandaivelu, K.; Edelman, E.R. Uremic serum and solutes increase post-vascular interventional thrombotic risk through altered stability of smooth muscle cell tissue factor. Circulation 2013, 127, 365-376. [CrossRef]

16. Addi, T.; Poitevin, S.; McKay, N.; El Mecherfi, K.E.; Kheroua, O.; Jourde-Chiche, N.; de Macedo, A.; Gondouin, B.; Cerini, C.; Brunet, P.; et al. Mechanisms of tissue factor induction by the uremic toxin indole-3 acetic acid through aryl hydrocarbon receptor/nuclear factor-kappa b signaling pathway in human endothelial cells. Arch. Toxicol. 2019, 93, 121-136. [CrossRef]

17. Borges, N.A.; Barros, A.F.; Nakao, L.S.; Dolenga, C.J.; Fouque, D.; Mafra, D. Protein-bound uremic toxins from gut microbiota and inflammatory markers in chronic kidney disease. J. Ren. Nutr. 2016, 26, 396-400. [CrossRef] 
18. Claro, L.M.; Moreno-Amaral, A.N.; Gadotti, A.C.; Dolenga, C.J.; Nakao, L.S.; Azevedo, M.L.V.; de Noronha, L.; Olandoski, M.; de Moraes, T.P.; Stinghen, A.E.M.; et al. The impact of uremic toxicity induced inflammatory response on the cardiovascular burden in chronic kidney disease. Toxins 2018, 10, 384. [CrossRef]

19. Jeong, Y.M.; Oh, M.H.; Kim, S.Y.; Li, H.; Yun, H.Y.; Baek, K.J.; Kwon, N.S.; Kim, W.Y.; Kim, D.S. Indole-3-acetic acid/horseradish peroxidase induces apoptosis in tccsup human urinary bladder carcinoma cells. Pharmazie 2010, 65, 122-126.

20. Kim, D.S.; Jeon, S.E.; Park, K.C. Oxidation of indole-3-acetic acid by horseradish peroxidase induces apoptosis in g361 human melanoma cells. Cell. Signal. 2004, 16, 81-88. [CrossRef]

21. Muslin, A.J. Mapk signalling in cardiovascular health and disease: Molecular mechanisms and therapeutic targets. Clin. Sci. 2008, 115, 203-218. [CrossRef] [PubMed]

22. Denise Martin, E.; De Nicola, G.F.; Marber, M.S. New therapeutic targets in cardiology: P38 alpha mitogen-activated protein kinase for ischemic heart disease. Circulation 2012, 126, 357-368. [CrossRef] [PubMed]

23. Kalantar-Zadeh, K.; Tortorici, A.R.; Chen, J.L.; Kamgar, M.; Lau, W.L.; Moradi, H.; Rhee, C.M.; Streja, E.; Kovesdy, C.P. Dietary restrictions in dialysis patients: Is there anything left to eat? Semin. Dial. 2015, 28, 159-168. [CrossRef] [PubMed]

24. Wright, M.; Southcott, E.; MacLaughlin, H.; Wineberg, S. Clinical practice guideline on undernutrition in chronic kidney disease. BMC Nephrol. 2019, 20, 370. [CrossRef] [PubMed]

25. Lin, Y.T.; Wu, P.H.; Lee, H.H.; Mubanga, M.; Chen, C.S.; Kuo, M.C.; Chiu, Y.W.; Kuo, P.L.; Hwang, S.J. Indole-3 acetic acid increased risk of impaired cognitive function in patients receiving hemodialysis. Neurotoxicology 2019, 73, 85-91. [CrossRef] [PubMed]

26. Lind, L.; Arnlov, J.; Lindahl, B.; Siegbahn, A.; Sundstrom, J.; Ingelsson, E. Use of a proximity extension assay proteomics chip to discover new biomarkers for human atherosclerosis. Atherosclerosis 2015, 242, 205-210. [CrossRef]

27. Benjamini Yoav, H.Y. Controlling the false discovery rate: A practical and powerful approach to multiple testing. J. R. Stat. Soc. Ser. B (Methodol.) 1995, 57, 12. [CrossRef]

28. Szklarczyk, D.; Santos, A.; von Mering, C.; Jensen, L.J.; Bork, P.; Kuhn, M. Stitch 5: Augmenting protein-chemical interaction networks with tissue and affinity data. Nucleic Acids Res. 2016, 44, D380-D384. [CrossRef]

29. Evenepoel, P.; Meijers, B.K.; Bammens, B.R.; Verbeke, K. Uremic toxins originating from colonic microbial metabolism. Kidney Int. Suppl. 2009, S12-S19. [CrossRef]

30. Brito, J.S.; Borges, N.A.; Esgalhado, M.; Magliano, D.C.; Soulage, C.O.; Mafra, D. Aryl hydrocarbon receptor activation in chronic kidney disease: Role of uremic toxins. Nephron 2017, 137, 1-7. [CrossRef]

31. Gouroju, S.; Rao, P.; Bitla, A.R.; Vinapamula, K.S.; Manohar, S.M.; Vishnubhotla, S. Role of gut-derived uremic toxins on oxidative stress and inflammation in patients with chronic kidney disease. Indian J. Nephrol. 2017, 27, 359-364.

32. Jourde-Chiche, N.; Dou, L.; Sabatier, F.; Calaf, R.; Cerini, C.; Robert, S.; Camoin-Jau, L.; Charpiot, P.; Argiles, A.; Dignat-George, F.; et al. Levels of circulating endothelial progenitor cells are related to uremic toxins and vascular injury in hemodialysis patients. J. Thromb. Haemost. 2009, 7, 1576-1584. [CrossRef] [PubMed]

33. Suzuki, Y.; Itoh, H.; Fujioka, T.; Sato, F.; Kawasaki, K.; Sato, Y.; Sato, Y.; Ohno, K.; Mimata, H.; Kishino, S. Association of plasma concentration of 4beta-hydroxycholesterol with cyp3a5 polymorphism and plasma concentration of indoxyl sulfate in stable kidney transplant recipients. Drug Metab. Dispos. 2014, 42, 105-110. [CrossRef]

34. Karu, N.; McKercher, C.; Nichols, D.S.; Davies, N.; Shellie, R.A.; Hilder, E.F.; Jose, M.D. Tryptophan metabolism, its relation to inflammation and stress markers and association with psychological and cognitive functioning: Tasmanian chronic kidney disease pilot study. BMC Nephrol. 2016, 17, 171. [CrossRef] [PubMed]

35. Mutsaers, H.A.; Wilmer, M.J.; Reijnders, D.; Jansen, J.; van den Broek, P.H.; Forkink, M.; Schepers, E.; Glorieux, G.; Vanholder, R.; van den Heuvel, L.P.; et al. Uremic toxins inhibit renal metabolic capacity through interference with glucuronidation and mitochondrial respiration. Biochim. Biophys. Acta 2013, 1832, 142-150. [CrossRef] [PubMed]

36. Gao, C.; Ji, S.; Dong, W.; Qi, Y.; Song, W.; Cui, D.; Shi, J. Indolic uremic solutes enhance procoagulant activity of red blood cells through phosphatidylserine exposure and microparticle release. Toxins 2015, 7, 4390-4403. [CrossRef] [PubMed] 
37. Wu, D.; Nishimura, N.; Kuo, V.; Fiehn, O.; Shahbaz, S.; Van Winkle, L.; Matsumura, F.; Vogel, C.F. Activation of aryl hydrocarbon receptor induces vascular inflammation and promotes atherosclerosis in apolipoprotein e-/- mice. Arterioscler. Thromb. Vasc. Biol. 2011, 31, 1260-1267. [CrossRef]

38. Boitano, A.E.; Wang, J.; Romeo, R.; Bouchez, L.C.; Parker, A.E.; Sutton, S.E.; Walker, J.R.; Flaveny, C.A.; Perdew, G.H.; Denison, M.S.; et al. Aryl hydrocarbon receptor antagonists promote the expansion of human hematopoietic stem cells. Science 2010, 329, 1345-1348. [CrossRef]

39. Cardoso, H.J.; Figueira, M.I.; Socorro, S. The stem cell factor (scf)/c-kit signalling in testis and prostate cancer. J. Cell Commun. Signal. 2017, 11, 297-307. [CrossRef]

40. Kitoh, T.; Ishikawa, H.; Ishii, T.; Nakagawa, S. Elevated scf levels in the serum of patients with chronic renal failure. Br. J. Haematol. 1998, 102, 1151-1156. [CrossRef]

41. Lennartsson, J.; Ronnstrand, L. Stem cell factor receptor/c-kit: From basic science to clinical implications. Physiol. Rev. 2012, 92, 1619-1649. [CrossRef] [PubMed]

42. Ashman, L.K. The biology of stem cell factor and its receptor c-kit. Int. J. Biochem. Cell Biol. 1999, 31, 1037-1051. [CrossRef]

43. Ali, S.R.; Hippenmeyer, S.; Saadat, L.V.; Luo, L.; Weissman, I.L.; Ardehali, R. Existing cardiomyocytes generate cardiomyocytes at a low rate after birth in mice. Proc. Natl. Acad. Sci. USA 2014, 111, 8850-8855. [CrossRef] [PubMed]

44. Kim, K.L.; Meng, Y.; Kim, J.Y.; Baek, E.J.; Suh, W. Direct and differential effects of stem cell factor on the neovascularization activity of endothelial progenitor cells. Cardiovasc. Res. 2011, 92, 132-140. [CrossRef] [PubMed]

45. Torsney, E.; Xu, Q. Resident vascular progenitor cells. J. Mol. Cell. Cardiol. 2011, 50, 304-311. [CrossRef]

46. Matsui, J.; Wakabayashi, T.; Asada, M.; Yoshimatsu, K.; Okada, M. Stem cell factor/c-kit signaling promotes the survival, migration, and capillary tube formation of human umbilical vein endothelial cells. J. Biol. Chem. 2004, 279, 18600-18607. [CrossRef]

47. Wang, C.H.; Verma, S.; Hsieh, I.C.; Hung, A.; Cheng, T.T.; Wang, S.Y.; Liu, Y.C.; Stanford, W.L.; Weisel, R.D.; Li, R.K.; et al. Stem cell factor attenuates vascular smooth muscle apoptosis and increases intimal hyperplasia after vascular injury. Arterioscler. Thromb. Vasc. Biol. 2007, 27, 540-547. [CrossRef]

48. Singla, D.K.; Singla, R.D.; Lamm, S.; Glass, C. Tgf-beta2 treatment enhances cytoprotective factors released from embryonic stem cells and inhibits apoptosis in infarcted myocardium. Am. J. Physiol. Heart Circ. Physiol. 2011, 300, H1442-H1450. [CrossRef]

49. Sato, E.; Saigusa, D.; Mishima, E.; Uchida, T.; Miura, D.; Morikawa-Ichinose, T.; Kisu, K.; Sekimoto, A.; Saito, R.; Oe, Y.; et al. Impact of the oral adsorbent ast-120 on organ-specific accumulation of uremic toxins: Lc-ms/ms and ms imaging techniques. Toxins 2017, 10, 19. [CrossRef]

50. Santana Machado, T.; Poitevin, S.; Paul, P.; McKay, N.; Jourde-Chiche, N.; Legris, T.; Mouly-Bandini, A.; Dignat-George, F.; Brunet, P.; Masereeuw, R.; et al. Indoxyl sulfate upregulates liver p-glycoprotein expression and activity through aryl hydrocarbon receptor signaling. J. Am. Soc. Nephrol. 2018, 29, 906-918.

51. Liabeuf, S.; Drueke, T.B.; Massy, Z.A. Protein-bound uremic toxins: New insight from clinical studies. Toxins 2011, 3, 911-919. [CrossRef] [PubMed]

52. Stockler-Pinto, M.B.; Soulage, C.O.; Borges, N.A.; Cardozo, L.; Dolenga, C.J.; Nakao, L.S.; Pecoits-Filho, R.; Fouque, D.; Mafra, D. From bench to the hemodialysis clinic: Protein-bound uremic toxins modulate nf-kappab/nrf2 expression. Int. Urol. Nephrol. 2018, 50, 347-354. [CrossRef] [PubMed]

53. Bataille, S.; Pelletier, M.; Sallee, M.; Berland, Y.; McKay, N.; Duval, A.; Gentile, S.; Mouelhi, Y.; Brunet, P.; Burtey, S. Indole 3-acetic acid, indoxyl sulfate and paracresyl-sulfate do not influence anemia parameters in hemodialysis patients. BMC Nephrol. 2017, 18, 251. [CrossRef] [PubMed]

54. Brito, J.S.; Borges, N.A.; Anjos, J.S.D.; Nakao, L.S.; Stockler-Pinto, M.B.; Paiva, B.R.; Cardoso-Weide, L.C.; Cardozo, L.; Mafra, D. Aryl hydrocarbon receptor and uremic toxins from the gut microbiota in chronic kidney disease patients: Is there a relationship between them? Biochemistry 2019, 58, 2054-2060. [CrossRef]

55. Watanabe, H.; Miyamoto, Y.; Otagiri, M.; Maruyama, T. Update on the pharmacokinetics and redox properties of protein-bound uremic toxins. J. Pharm. Sci. 2011, 100, 3682-3695. [CrossRef]

56. De Smet, R.; Dhondt, A.; Eloot, S.; Galli, F.; Waterloos, M.A.; Vanholder, R. Effect of the super-flux cellulose triacetate dialyser membrane on the removal of non-protein-bound and protein-bound uraemic solutes. Nephrol. Dial. Transplant. 2007, 22, 2006-2012. [CrossRef] 
57. Deltombe, O.; Van Biesen, W.; Glorieux, G.; Massy, Z.; Dhondt, A.; Eloot, S. Exploring protein binding of uremic toxins in patients with different stages of chronic kidney disease and during hemodialysis. Toxins 2015, 7, 3933-3946. [CrossRef]

58. Eloot, S.; Van Biesen, W.; Glorieux, G.; Neirynck, N.; Dhondt, A.; Vanholder, R. Does the adequacy parameter $\mathrm{kt} / \mathrm{v}$ (urea) reflect uremic toxin concentrations in hemodialysis patients? PLoS ONE 2013, 8, e76838. [CrossRef]

(C) 2020 by the authors. Licensee MDPI, Basel, Switzerland. This article is an open access article distributed under the terms and conditions of the Creative Commons Attribution (CC BY) license (http://creativecommons.org/licenses/by/4.0/). 